\title{
DIFFERENTIAL OPERATORS WITH A PURELY CONTINUOUS SPECTRUM
}

\author{
KURT KREITH
}

We consider a formally self-adjoint differential operator

$$
L=-\frac{1}{r(x)} \frac{d}{d x}\left(p(x) \frac{d}{d x}\right)+q(x)
$$

whose coefficients are positive and of class $C^{1}$ on $[0, \infty)$. Let $\mathscr{\&}_{r}^{2}(0, \infty)$ denote the class of complex valued functions $v(x)$ which satisfy

$$
\|v\|^{2}=\int_{0}^{\infty} r|v|^{2} d x<\infty
$$

and assume that $L$ is in the limit point case at $\infty$. Then the boundary value problem

$$
\begin{aligned}
L u & =\lambda u, \\
u(0) & =0 ; \quad\|u\|<\infty
\end{aligned}
$$

gives rise to an operator $\bar{L}$ which is self-adjoint in $\mathscr{L}_{r}^{2}$.

The question which we shall investigate is: When is the spectrum of $\bar{L}$ purely continuous? One such result is given in [1, Chapter 9 , problem 4] for the case $p=r \equiv 1$. This problem states that if

$$
\int_{0}^{\infty}|q(x)| d x<\infty
$$

then the spectral function $\rho(\lambda)$ corresponding to $\bar{L}$ is continuous (and in fact of class $C^{1}$ ) on $[0, \infty)$. A different result in this direction is given by the following ${ }^{1}$

THEOREM. If $p^{\prime} \leqq 0, r^{\prime} \geqq 0$, and $(r q)^{\prime} \leqq 0$ on $(0, \infty)$, then the spectrum of $\bar{L}$ is purely continuous.

PROOF. Since the eigenfunction corresponding to any isolated eigenvalue of $\bar{L}$ belongs to $\mathscr{L}_{2}^{r}$, it is sufficient to show that for any $\lambda>0$ every solution of

Received by the editors February 1, 1962.

${ }^{1}$ Referee's comment. The hypotheses of the author's theorem automatically ensure that $L$ is in the limit point case at $x=+\infty$, so that it is unnecessary to make this an additional assumption. 


$$
\begin{aligned}
L u & =\lambda u, \\
u(0) & =0
\end{aligned}
$$

fails to satisfy the condition $\lim _{t \rightarrow \infty} \int_{0}^{t} r|u|^{2} d x<\infty$. If $u$ is a solution of $\left(1^{\prime}\right)$ then we have

$$
\left(p u^{\prime \prime}+p^{\prime} u^{\prime}+r(\lambda-q) u\right) u^{\prime}=0 .
$$

This is equivalent to

$$
\left(p u^{\prime 2}\right)^{\prime}+p^{\prime} u^{\prime 2}+\left(r(\lambda-q) u^{2}\right)^{\prime}-(r(\lambda-q))^{\prime} u^{2}=0 .
$$

Integrating from 0 to $t$

$$
\begin{aligned}
\int_{0}^{t}\left(-p^{\prime} u^{\prime 2}+(r(\lambda-q))^{\prime} u^{2}\right) d x+p(0) u^{\prime}(0)^{2} & \\
& =p(t) u^{\prime}(t)^{2}+r(\lambda-q) u(t)^{2} .
\end{aligned}
$$

Let $k=p(0) u^{\prime}(0)^{2}$. Since $p(0)>0$ and $u^{\prime}(0) \neq 0, k>0$. Our hypotheses also guarantee that the above integral is a monotonic increasing function of $t$. Therefore we have

$$
\int_{0}^{T}\left(p u^{\prime 2}+r(\lambda-q) u^{2}\right) d x \geqq k T .
$$

We shall refer to this inequality later.

If $u$ is a solution of $\left(1^{\prime}\right)$ we also have

$$
\begin{aligned}
& 0=\int_{0}^{t}\left(\left(p u^{\prime}\right)^{\prime}+r(\lambda-q) u\right) u d x, \\
& \left.0=-\int_{0}^{t} p u^{\prime 2} d x+\int_{0}^{t} r(\lambda-q) u^{2} d x+p u^{\prime} u\right]_{0}^{t} .
\end{aligned}
$$

Or finally

$$
\int_{0}^{t}\left(p u^{\prime 2}+r(\lambda-q) u^{2}\right) d x=2 \int_{0}^{t} r(\lambda-q) u^{2} d x+\frac{1}{2} p(t)\left(u(t)^{2}\right)^{\prime}
$$

We consider two possibilities:

A. If there exists a positive constant $M$ for which $\left(u(t)^{2}\right)^{\prime}>0$ for all $t>M$, then clearly $u$ does not belong to $\mathfrak{L}_{r}^{2}$.

B. If there exists a sequence of positive numbers $\left\{t_{n}\right\}$ for which $t_{n} \uparrow \infty$ and $\left(u\left(t_{n}\right)^{2}\right)^{\prime} \leqq 0$ then by (2) and (3) we conclude that

$$
2 \int_{0}^{t_{n}} r(\lambda-q) u^{2} d x \geqq \int_{0}^{t_{n}}\left(p u^{\prime 2}+r(\lambda-q) u^{2}\right) d x \geqq k t_{n} .
$$


1963] DIFFERENTIAL OPERATORS WITH A PURELY CONTINUOUS SPECTRUM 811

Since $r q$ is positive we have

$$
\int_{0}^{t_{n}} r u^{2} d x \geqq \frac{k}{2 \lambda} t_{n} .
$$

Again we conclude that $u \notin \mathcal{L}_{r}^{2}$.

\section{BibliogRAPHy}

1. E. Coddington and N. Levinson, Theory of ordinary differential equations, McGraw-Hill, New York, 1955.

2. F. Rellich, Über das Asymptotische Verhalten der Lösungen von $\Delta u+\lambda u=0$ in unendlichen Gebieten, Jber. Deutsch. Math.-Verein. 53 (1943), 57-65.

University of California, Davis 